work done by a hypertrophied organ nearly equals that done by two of smaller size, then the bladder must have received a sufficient quantity of urine still to have remained what it really should be-" a retention pouch,"-and, in face of that duty, conld not easily have sunk into utter insignificance or absolute retirement. Destruction of the kidneys is not followed by disappearance of the bladder, for we know that where one kidney has for long been useless to the economy, so far as contribution is concerned, from impacted calculus in the ureter or pelvis, the supervention of hydronephrosis in the other kidney, though resulting in deficient elimination of urine, is not followed by any special changes in the bladder.

In the left kidney we have evidence of congenital deformity in the entrances and exits of vessels. The renal artery entered at the hilus ; the renal vein issued from the superior extremity of the organ, and the ureter was connected with a peculiarly-shaped pelvis at the inferior extremity of the kidney. With this anomaly in the disposition of parts in the upper portion of the genito-urinary tract, with the evidence of congenital malformation in the shape of the kidney and its accessories, I think we are almost at liberty to state that the "development of a bladder has in some way or other been interfered with"; rather than having preexisted, it has disappeared.

Supposing the case to be one of pre-existence and subsequent disappearance of the bladder, is the condition of the left ureter and kidney such as we would expect to find in such a probability? Is it possible, too, to have the left ureter alone dilating and taking on itself the function of a urinary bladder, while its neighbour at death presents, at one part at least, a normal calibre? So far as the right ureter is concerned, its calibre was only normal for a very short distance from the kidney. Lower down it was so firmly bound down amongst inflammatory adhesions as to be no longer a patent tube, so that whether in the earlier part of the patient's lifetime it complemented the function of the left ureter it is impossible to say; at death it was useless. What was formerly a patent tube was now only a fibrous cord. The interesting features reside entirely in the anatomical peculiarities in the left side of the body. Here we have a widely dilated ureter, like the coil of a chlld's small intestine, constricted above at a short distance from the left kidney, leaving that organ unaffected, and on tracing this ureter downwards we find that it tapers so that just before joining the urethra it is markedly narrowed. This terminal constriction must have served a beneficial end. A certain amount of natural or spasmodic contraction at this point would prevent a continual dribbling away of urine, and thus allow of more comfort to the patient. But in saying this I imply that this contraction of the ureter is natural, is congenital if you will, put there to serve a good end, and that this had been accomplished, for it this state of matters had been of short duration the same end would not have been served. Constrietion of the ureter causes accumulation of fluid behind that point, and the fluid in its accumulation exerts a deteriorating influence on the structures lying further back. When the ureter is obstrueted, either by pressure from without or when the cause of obstruction is a calculus within, we have a hydronephrosis established, of the existence of which in this case, or even the tendency thereto, there is not the slichtest evidence. The condition of hydronephrosis would, I think, have been established had the npper constriction near the kidney not existed, or-and this is more to the point-had the bladder disappeared. This disease has not been developed, because nature from the beginning had suited herself to existing conditions, the left ureter acting, it is true, somewhat imperfectly, but still fairly, the part of a bladder.

This case is not unique. Cases of absence of the bladder have already been published, but they are rare. In the article "Bladder," in Todd's Cyclopredia of Anatomy and Physiology, to whichmy attention has been very kindly drawn
by Professor Allen Thomson, a few cases of the absence of this organ are recorded, in some of which the ureters either terminated in the urethra or were inserted into the rectum, while in others they communicated with the vagina. Of the first species the following are examples:- "Lieutand mentions the case of a man, aged thirty-five, in whom the ureters, the capacity of which was much augmented, terminated immediately below the pubis, near the orifice of the urethra. Binninger describes the case of Abraham Clef, in whom there was no urinary bladder, and the ureters opened into the urethra." Of the second snecies "we have in the seventh volume of the Philosophical Transactions the history given by Richardson of a lad who lived to the age of seventeen without ever having passed urine by the urethra, and who had still enjoyed good health. The only inconvenience he suffered was a consequence of the passage of the urine into the rectum, by which a troublesome diarrhœa was kept up. Camper speaks of five similar cases, one of which was a female. Klein also speaks of a case. of the third species cases are cited by Haller and Schrader." There is also a case mentioned by Phillips of a female fœtus in which the ureters opened through the abdominal parietes on each side of the pubic region in the form of little pouches.

\section{CASE OF POISONING BY THREE DRACHMS OF PRUSSIC ACID; OPHTHALMOSCOPIC SIGNS OF DEATH.}

\section{BY A. B. KELLY, L.R.C.P. ED., M.R.C.S. ENG.}

THE following case of poisoning by prussic acid will, I think, be of interest on account of the large dose which was taken and the length of time which elapsed before it proved fatal.

At 6.10 P.M. on Oct. 18th I left the house. A page-boy, aged sixteen, was standing in the hall, apparently well. At 6.30 precisely I returned, and, while in my consulting room with a patient, heard a noise of heavy breathing. I directed inquiries to be made as to the cause of this. At $6.35 \mathrm{I}$ was informed by one of the maid-servants, who had got up on a chair and looked over a partition which divided the lad's bedroom from the hall, that he was pale and foaming at the mouth. I immediately got over the partition and opened the door from within, the latch being one which from the outside opened only with a key. I found him on his back on the bed. He was perfectly insensible; very livid; there was mucus without blood about his mouth ; his eyes were open and glassy, and the pupils dilated. The respiration was hurried and stertorous. There were no convulsions although these are generally a result in poisoning by prussic acid. There was no involuntary passage of fæces or of urine. The pulse was full and rapid at first, but gradually became weaker. There was no vomiting. On the floor by the bedside stood a bottle with the stopper replaced. The lad had taken as much as three drachms. Cold affusion and artificial respiration were at once resorted to, and, with the kind assistanee of Dr. Buzzard, who arrived shortly after I had entered the bed-room, a magneto-induced current was employed for upwards of a quarter of an hour.

The average dose proving fatal is forty minims of the B.P., though recovery has taken place after one drachm has been swallowed. Two to ten minutes is given as the average period of life after two drachms or more, but in this case the lad lived, I should think, some twenty minutes after the poison was taken.

The stertorous breathing observed in this case has not, I think, been hitherto recorded in poisoning by prussic acid. It must be observed that the boy had just had his tea prior to taking the poison. His family history indicated no hereditary insanity or epilepsy. His father and sister are living, and are both healthy. He had been under my observation for one year, and only during the last week of his life had I perceived anything strange about his habits. I have, however, since learnt that he had pointed a small pistol at his fellow-servants, and had actually discharged a bullet within range of one of them; also that he had placed his head in a jack-towel hanging from a door, which caused him to turn black in the face, and, when remoustrated with, he said, "Oh, it's all right; I'm only larking."

Remarkable facts in relation to the case are, first, the presence of stertorous breathing and absence of convulsions. Stertorous breathing would appear to be exceptional in cases of poisoning by prussic acid, and to indicate profound insensibility. In Palmer's poisoning case at Rugeley it was contended that the fact of the deceased having had stertorous breathing was a proof that he had died from apoplexy, and not, as was alleged, from prussic acid. Again, the fact that the lad replaced the stopper in the bottle, and put it on the floor, further indicates that insensibility and physical ex. 
haustion could not have come on as rapidly as they usually do in these cases.

Dr. Buzzard has obliged me with the following note of his observations on the case.

"When I saw the patient, some fifteen minutes after the poison had been taken, he was lying on his back profoundly insensible, the eyes nearly closed, the pupils large and insensitive to light. The body was cool and moist, the muscular system relaxed and free from any convulsive twitchings, the mouth half open, showing the tongue of a dark-red colour. The lips were of a purplish tint, and the thips of the fingers livid. There was no pulsation at the wrist, nor could any action of the heart be perceived by auscultation. Dr. Kelly was applying artificial respiration, and when this was discontinued for a minute or two it was noticed that a spontaneous respiratory act took place, and was followed by another after an interval of some fifty or sixty seconds. Faradisation of the phrenic nerves was then employed, but without effect; and when several minutes had elapsed without the least trace of automatic respiration, it was concluded that life was extinct. As, however, there had been no sign whatever to mark the moment of transition, I was anxious to satisfy myself that further efforts would be unavailing, and, having an ophthalmoscope with me, I examined one of the eyes, with the following result. The usual brilliant red glow from the choroid was entirely wanting, and its place was occupied by a very pale violetgrey tint. The optic disc, of a dull grey-white tone, was very ill-defined. The retinal arteries could be discerned with the greatest difficulty as exceedingly narrow threads. The veins, on the other hand, were easily traced, but appeared to be unevenly and imperfectly charged with blood. The observation was somewhat obstructed by a peculiar broken-up-like condition of the media - whether of the cornea, lens, or vitreous, I could not determine-which gave one the idea of looking through cooked tapioca. Observations are not yet numerous enough to enable us to say that the ophthalmoscope is always to be absolutely relied upon as a test of death, but as in this instance circumstances combined to prove that life was extinct when the observation was made, a record of the conditions found may be of service."

Mount-street, Grosvenor-square.

\section{CASE OF COMPLETE RIGOR MORTIS OF BOTH LEGS FOURTEEN HOURS BEFORE DEATH}

BY ALFRED FINCH, M.R.C.S., LATELY HOUSE-PHYSICIAN TO GUY'S HOSPITAL.

ON Friday, Sept. 26th, 1879, I was called at 4 P.M. to see Mrs. G. A- , aged sixty-five, the widow of a clergyman, and a complete stranger to me. I was told that on attempting to come down stairs that morning she lost the power of motion in her legs, which had felt numb whilst dressing, and that for the last fortnight she had taken absolutely no food, though always sitting down to meals with her three daughters, but had drunk small quantities of lupulin, a nonalcoholic drink. During this period she had gone about as usual, going to church on the previous Sunday, and had refused to see any medical man. About a year ago she had gone without food in a similar manner for a week when suffering from some mental distress.

The patient was lying on her back in bed with her head propped up on pillows. She received me without opposition, and spoke cheerfully. In answer to questions she described herself as quite well, said she had not had any appetite lately, that her legs felt cold and numb when she got up in the morning, and afterwards gave way under her, but that now they did not feel cold.

On examination both lower extremities were stone cold as high as Poupart's ligament. There was no cedema. The skin was loose, but had lost its elasticity, so that on taking it between the fingers and pinching it into folds it retained some of them when relaxed. There was perfect muscular rigidity, and the knee could not be flexed with moderate force (the servant had noticed this first at 11 A.M.) No pulsation could be felt in either femorals. A pin thrust in was unnoticed and produced no reflex action. The surface of abdomen was warm, the boundary of sensation and warmth being sharply defined at Poupart's ligament; both completely absent below, but distinct above. There was no loss of power or sensation in the upper extremities, but the fingers were cold and livid. The facial expression was somewhat cadaverous. The whole body was very fairly nourished. The heart-sounds were feeble and slow, pulse barely perceptible at wrist. The breath had a peculiar earthy smell; the tongue was dry and coated with a thin white fur.

She was remored at once to a room with a fire, heat applied externally, and mustard to chest, and after a slight attempt at refusal she swallowed half a pint of beef-tea and brandy. She was left at 5.30 P.M. with instructions that beef-tea and brandy should be given every hour, with a mixture of ether and ammonia. At S P.M. the patient had swallowed nearly a pint of beef-tea at intervals, but since 7 o'clock she had become drowsy and breathed more deeply. Her state was now one of semi-collapse, drowsy, and yet easily roused and able to answer questions; the pulse at wrist imperceptible; respiration rapid and noisy; and she was very restless, throwing her arms about a good deal. Sinapisms were applied to chest again, but she continued to become more collapsed.

At 9 P.M. Dr. Robert Finch saw her and tried the effect of placing the hands in very hot water. This roused her considerably, and made her cry out, but not intelligibly. There was evidently great hyperæesthesia of the hands, but cloths wrung out of almost boiling water and applied to the legs were unheeded. However, the good effect was not per. manent; she became quite unconscious at 11.30 P.M. and died at 1.30 A.M. For about an hour before death the respiration was peculiar, that known as Cheyne-Stokes' respiration, at times noisy and rapid, then sinking low and feeble, and after a time becoming rapid and noisy again, and the various periods succeeding each other with regularity.

Necropsy, Sept. 30th. - Rigor mortis had disappeared. The attendant who performed the necessary offices told me that as early as two hours after death the body was quite free from rigor. The body was well nourished, the fat thick over chest and abdomen. On opening abdomen, the omentum and mesentery were thickly infiltrated with fat, and the appendices epiploïcæ particularly fatty. The stomach contained a small amount of green fluid; the small and large intestine were empty, except a little fæces in the rectnm. The liver was small but healthy; the gall-bladder full of bile, but not distended; the spleen was small but healthy; the kidneys were healthy.-Heart: Extensive fatty deposit on the external surface; the walls of both ventricles were in a state of extreme fatty degeneration, very pale in colour and readily broken through by the finger. The degenera. tion extended from without inwards, the innermost fibres not being so extremely altered; and the columnæ carnex and musculi papillares were apparently healthy. The valves were also healthy. The coronary arteries were extensively atheromatous and much obstructed by calcareous deposits. The ascending and transverse aorta were thickened and atheromatous; the descending aorta was very much changed and ulcerated in several places, and on the posterior wall, just above the bifurcation, there was a large ulcerated surface and calcareous plate. The iliac and femoral arteries were filled with coloured loose clots; their internal surface was smooth and healthy.

Remarks.-From the above facts I can come to no other conclusion than that the lower extremities of the patient had passed into a state of rigor mortis. The stone coldness of the affected parts, and the absence of any circulation, combined with the other appearances, notably the peculiar want of elasticity in the skin, exclude the possibility of spasm due to nervous origin. It appears to me that, owing to disease of the heart and aorta, and the fourteen days starvation, possibly also to the presence of a calcareous plate at the bifurcation of the aorta, which in some degree must have obstructed the free passage of blood to the iliac arteries, the circulation became extremely feeble, and ceased entirely in the lower extremities several hours before the heart failed. I do not know of any parallel case on record, but Rossbach, in Virchow's Archiv, vol, xli., p. 558 , has described a rigor mortis beginning during the last moments of life, and, as is well known, muscular action may pass occasionally directly and at once into cadaveric rigidity. If, however, we accept the usual explanation of rigor mortis-viz., that it is due to the coagulation of the myosin, 